\title{
Fibrinogen in relation to degree and composition of coronary plaque on intravascular ultrasound in patients undergoing coronary angiography
}

\author{
Buljubasic, Nermina ; Akkerhuis, K Martijn ; Cheng, Jin M ; Oemrawsingh, Rohit M ; Garcia-Garcia, \\ Hector M ; de Boer, Sanneke P M ; Regar, Evelyn ; van Geuns, Robert-Jan M ; Serruys, Patrick W J C \\ ; Boersma, Eric ; Kardys, Isabella
}

\begin{abstract}
OBJECTIVE: The aim of this study was to provide additional insight into the role of fibrinogen in coronary artery disease by investigating the associations between plasma fibrinogen with both degree and composition of coronary atherosclerosis as determined by virtual histology-intravascular ultrasound. PATIENTS AND METHODS: In 581 patients undergoing coronary angiography for acute coronary syndrome (ACS) or stable angina pectoris, preprocedural blood samples were drawn for fibrinogen, Creactive protein (CRP), interleukin-6, and plasminogen activator inhibitor-1 measurements, and virtual histology-intravascular ultrasound of a nonculprit coronary artery was performed. The degree [plaque volume, plaque burden (PB), and lesions with $\mathrm{PB} 70 \%$ ] and the composition of coronary atherosclerotic plaque (fibrous, fibrofatty, dense calcium, necrotic core tissue, and thin-cap fibroatheroma lesions) were assessed. RESULTS: Fibrinogen showed a tendency toward a positive association with PB [ (95\% CI): 2.55 (-0.52-5.61) increase in $\mathrm{PB}$ per $\ln (\mathrm{g} / \mathrm{l})$ fibrinogen, $\mathrm{P}=0.09]$, which was driven significantly by an association in the ACS subgroup [ (95\% CI): 4.11 (0.01-8.21) increase in PB per $\ln (\mathrm{g} / \mathrm{l})$ fibrinogen, $\mathrm{P}=0.049$ ]. Fibrinogen was also related to the presence of lesions with $\mathrm{PB} 70 \%$ or more in both the full cohort [OR (95\% CI): 2.27 (1.17-4.43), $\mathrm{P}=0.016$ ] and ACS patients [OR (95\% CI): 2.92 (1.17-7.29), P=0.022]. All associations were independent of established cardiovascular risk factors, but not CRP. Interleukin-6 and plasminogen activator inhibitor-1 did not provide incremental value to fibrinogen when examining the associations with degree of atherosclerosis. Substantial associations with plaque composition were absent. CONCLUSION: Fibrinogen is associated with degree of coronary atherosclerosis, especially in ACS patients. However, whether this association is independent of CRP might be questioned and needs further investigation.
\end{abstract}

DOI: https://doi.org/10.1097/MCA.0000000000000442

Posted at the Zurich Open Repository and Archive, University of Zurich

ZORA URL: https://doi.org/10.5167/uzh-146178

Journal Article

Published Version

Originally published at:

Buljubasic, Nermina; Akkerhuis, K Martijn; Cheng, Jin M; Oemrawsingh, Rohit M; Garcia-Garcia, Hector M; de Boer, Sanneke P M; Regar, Evelyn; van Geuns, Robert-Jan M; Serruys, Patrick W J C; Boersma, Eric; Kardys, Isabella (2017). Fibrinogen in relation to degree and composition of coronary plaque on intravascular ultrasound in patients undergoing coronary angiography. Coronary artery disease, 28(1):23-32. 
DOI: https://doi.org/10.1097/MCA.0000000000000442 


\section{Fibrinogen in relation to degree and composition of coronary plaque on intravascular ultrasound in patients undergoing coronary angiography}

Nermina Buljubasic, K. Martijn Akkerhuis, Jin M. Cheng, Rohit M. Oemrawsingh, Hector M. Garcia-Garcia, Sanneke P.M. de Boer, Evelyn Regar, Robert-Jan M. van Geuns, Patrick W.J.C. Serruys, Eric Boersma and Isabella Kardys

Objective The aim of this study was to provide additional insight into the role of fibrinogen in coronary artery disease by investigating the associations between plasma fibrinogen with both degree and composition of coronary atherosclerosis as determined by virtual histologyintravascular ultrasound.

Patients and methods In 581 patients undergoing coronary angiography for acute coronary syndrome (ACS) or stable angina pectoris, preprocedural blood samples were drawn for fibrinogen, C-reactive protein (CRP), interleukin-6, and plasminogen activator inhibitor-1 measurements, and virtual histology-intravascular ultrasound of a nonculprit coronary artery was performed. The degree [plaque volume, plaque burden (PB), and lesions with $\mathrm{PB} \geq 70 \%$ ] and the composition of coronary atherosclerotic plaque (fibrous, fibrofatty, dense calcium, necrotic core tissue, and thin-cap fibroatheroma lesions) were assessed.

Results Fibrinogen showed a tendency toward a positive association with PB [ $\beta(95 \% \mathrm{Cl}): 2.55(-0.52-5.61)$ increase in PB per $\ln (\mathrm{g} / \mathrm{l})$ fibrinogen, $P=0.09$, which was driven significantly by an association in the ACS subgroup [ $\beta$ (95\% $\mathrm{Cl})$ : 4.11 (0.01-8.21) increase in PB per $\ln (\mathrm{g} / \mathrm{l})$ fibrinogen, $P=0.049$ ]. Fibrinogen was also related to the presence of lesions with PB $70 \%$ or more in both the full cohort [OR $(95 \%$

\section{Introduction}

Elevated plasma fibrinogen levels have been associated with coronary events both in apparently healthy individuals [1-3] and in patients with manifest coronary artery disease (CAD) [4-7]. Underlying mechanisms that may account for this association have not been fully elucidated as yet, but fibrinogen is known to play an important role in thrombosis [8] and might as well influence the progression of atherosclerotic plaque formation $[9,10]$. In addition, clinical evidence has shown that fibrinogen is correlated with the severity of atherosclerosis on both coronary angiography and carotid ultrasonography [11-15]. These noninvasive imaging techniques evaluate the unobstructed part of the lumen and have not contributed toward elucidating potential mechanisms of the involvement of fibrinogen in atherosclerosis. In contrast, invasive
Cl): $2.27(1.17-4.43), P=0.016$ ] and ACS patients [OR $(95 \% \mathrm{Cl})$ : 2.92 (1.17-7.29), $P=0.022$ ]. All associations were independent of established cardiovascular risk factors, but not CRP. Interleukin-6 and plasminogen activator inhibitor-1 did not provide incremental value to fibrinogen when examining the associations with degree of atherosclerosis. Substantial associations with plaque composition were absent.

Conclusion Fibrinogen is associated with degree of coronary atherosclerosis, especially in ACS patients. However, whether this association is independent of CRP might be questioned and needs further investigation. Coron Artery Dis 28:23-32 Copyright (c) 2016 Wolters Kluwer Health, Inc. All rights reserved.

Coronary Artery Disease 2017, 28:23-32

Keywords: acute coronary syndrome, atherosclerosis, coronary artery disease, fibrinogen, intravascular ultrasonography

Department of Cardiology, Erasmus MC, Rotterdam, the Netherlands

Correspondence to Isabella Kardys, MD, Department of Cardiology, Erasmus MC Room Ba-561, PO Box 2040, 3000 CA Rotterdam, the Netherlands Tel: +31 10703 5048; fax: + 3110704 4759; e-mail: i.kardys@erasmusmc.nl

Received 11 July 2016 Revised 15 September 2016 Accepted 21 September 2016

assessment of coronary plaque by virtual histologyintravascular ultrasound (VH-IVUS) not only accurately quantifies coronary atherosclerosis but also enables in-vivo analysis of coronary plaque composition as well as plaque vulnerability. Thus, this technique provides information on the structure and composition of the arterial wall itself and could add insights into the pathophysiology of coronary atherosclerosis [16].

Until now, the association between fibrinogen and invivo coronary plaque characteristics has only been examined in two IVUS studies $[17,18]$. The first study had a modest study sample size of 60 patients and applied grayscale IVUS to quantify coronary atherosclerosis, which did not allow for assessment of the composition and vulnerability of the coronary plaques 
[17]. The second study did use VH-IVUS, but again had limited sample size (only 75 patients) [18]. Furthermore, although this study examined necrotic core (NC), it did not assess plaque vulnerability by determining thin-cap fibroatheromas (TCFAs) [18].

Therefore, we investigated the association of plasma fibrinogen with the degree, composition, and vulnerability of coronary atherosclerosis as determined by $\mathrm{VH}-$ IVUS, as well as with 1-year cardiovascular outcome, in a relatively large study population consisting of 581 patients undergoing coronary angiography. In addition, to provide a broader view on the pathophysiological relationship between fibrinogen and coronary atherosclerosis, we examined the incremental value of the inflammatory and prothrombotic markers C-reactive protein (CRP), interleukin-6 (IL-6), and plasminogen activator inhibitor1 (PAI-1) to fibrinogen.

\section{Patients and methods}

The rationale and design of the European Collaborative Project on Inflammation and Vascular Wall Remodeling in Atherosclerosis - Intravascular Ultrasound (ATHERO REMO-IVUS) study have been approved by the medical ethics committee of the Erasmus MC (Rotterdam, the Netherlands) and are described in detail elsewhere [19]. The study is registered on ClinicalTrials.gov, number NCT0 1789411. Briefly, 581 patients undergoing diagnostic coronary angiography or percutaneous coronary intervention for acute coronary syndrome (ACS) or stable angina pectoris (SAP) were included. Written informed consent was obtained from all included patients. Baseline clinical and procedural characteristics were derived from medical records. Blood plasma samples were drawn before the procedure and stored at a temperature of $-80^{\circ} \mathrm{C}$. Frozen EDTA-plasma samples were transported under controlled conditions to Myriad RBM (Austin, Texas, USA), where fibrinogen, IL-6, and PAI-1 levels were measured successfully in 570 samples (ACS, $n=309$; SAP, $n=261$ ) using a validated, quantitative, multiplexed immunoassay (Custom HumanMAP; Myriad RBM). CRP measurements were performed in serum samples at the clinical laboratory of Erasmus MC using an immunoturbidimetric high-sensitivity assay (Roche Diagnostics Ltd, Rotkreuz, Switzerland) on the Cobas 8000 Modular Analyzer Platform (Roche Diagnostics Ltd). Coefficients of variation were $8 \%$ or less, $10 \%$ or less, $11 \%$ or less, and $4 \%$ or less for fibrinogen, IL-6, PAI-1, and CRP, respectively. Following the standard coronary angiography, VH-IVUS data were acquired in a nonculprit coronary artery with the Volcano s5/s5i Imaging System (Volcano Corp., San Diego, California, USA) using a Volcano Eagle Eye Gold IVUS catheter (20 MHz) [19]. The degree and composition of the atherosclerotic plaque were assessed offline in a dedicated core-lab as described previously [19]. Plaque volume was defined as the total volume of the external elastic membrane occupied by atheroma and was normalized for the length of the imaged segment. Plaque burden $(\mathrm{PB})$ was defined as plaque and media cross-sectional area divided by external elastic membrane cross-sectional area and is presented as a percentage. Atherosclerotic plaque composition was characterized into fibrous (FI), fibrofatty, dense calcium, and NC. Three types of high-risk lesions were identified: (i) VH-IVUS-derived TCFA lesions (presence of $>10 \%$ confluent NC in direct contact with the lumen); (ii) lesions with large $\mathrm{PB}(\geq 70 \%)$; and (iii) lesions with a minimal luminal area $4.0 \mathrm{~mm}^{2}$ or less.

Clinical follow-up started at inclusion and lasted 1 year. The primary clinical endpoint consisted of major adverse cardiovascular events (MACEs), which was a composite of death, ACS, or unplanned coronary revascularization [19]. ACS was defined as the clinical diagnosis of nonST-segment elevation myocardial infarction or unstable angina pectoris $[20,21]$. Unplanned coronary revascularization was defined as any repeat percutaneous coronary intervention or coronary artery bypass grafting that was not foreseen at the index procedure. Endpoints were adjudicated by a clinical events committee on the basis of original source data.

Normally distributed continuous variables are presented as mean $\pm \mathrm{SD}$, whereas non-normally distributed continuous variables are presented as median (interquartile range). Categorical variables are presented as numbers and percentages. Variables with non-normal distributions, determined by visual inspection of the histograms, were natural logarithmically (ln) transformed or were transformed using the square root for further analyses. First, statistical analyses were carried out in the full cohort. Subsequently, they were stratified on indication for catheterization (ACS vs. SAP) to account for potential differences in pathophysiology. Associations of fibrinogen with segment VH-IVUS parameters were examined using linear regression analyses with continuous lntransformed fibrinogen as the independent variable. The results are presented as $\beta$ increase in (transformed) segment VH-IVUS parameter per unit increase in lntransformed fibrinogen concentration, with $95 \%$ confidence intervals (CIs). Logistic regression analyses were carried out for associations between fibrinogen and the presence of high-risk lesions with continuous lntransformed fibrinogen as the independent variable. The results are presented as odds ratios (ORs) per unit increase in ln-transformed fibrinogen concentration, with 95\% CIs. All statistical analyses were carried out univariably (model 1 ) and multivariably (models 2 and 3 ). Potential confounders were selected on the basis of previous literature (age, sex, smoking, diabetes mellitus, dyslipidemia, hypertension, indication for catheterization) and entered as covariates into the multivariable models (model 2). Subsequently, CRP was added to the models (model 3) as CRP is the most widely studied inflammatory marker in cardiovascular disease and has been suggested to carry similar predictive value for MACE as fibrinogen [22]. 
Afterwards, we examined whether the inflammatory markers IL-6 and CRP and the prothrombotic marker PAI-1 provide incremental value to elevated levels of fibrinogen with respect to the degree of atherosclerosis. For this purpose, these markers were dichotomized [CRP and PAI-1: below and above the median; IL-6: detectable $(37.7 \%)$ vs. nondetectable $(62.3 \%)$ levels], and degree of atherosclerosis was examined in patients according to both the categories of these markers and dichotomized categories of fibrinogen (above and below median). ANOVA trend tests were used to discern trends across the categories.

Finally, we examined associations of fibrinogen with clinical endpoints after 1 year of follow-up with Cox proportional hazard regression analyses.

\section{Results}

Baseline clinical and procedural characteristics are presented in Table 1 . The mean \pm SD age of the patients was $61.5 \pm 11.4$ years $(75 \%$ were men); $54 \%$ of the patients were admitted with ACS and $46 \%$ had SAP. The median (interquartile range) fibrinogen level was 3.5 (2.9-4.4) $\mathrm{g} / \mathrm{l}$ in the full cohort. In ACS and SAP patients,

Table 1 Baseline patient and procedural characteristics

\begin{tabular}{|c|c|c|c|}
\hline & $\begin{array}{l}\text { Full cohort } \\
(n=570)\end{array}$ & $\begin{array}{c}\text { ACS patients } \\
(n=309)\end{array}$ & $\begin{array}{l}\text { SAP patients } \\
\quad(n=261)\end{array}$ \\
\hline \multicolumn{4}{|l|}{ Patient characteristics } \\
\hline Age (mean \pm SD) (years) & $61.5 \pm 11.4$ & $59.7 \pm 11.9$ & $63.6 \pm 10.3$ \\
\hline Male sex $[n(\%)]$ & $430(75.4)$ & $227(73.5)$ & $203(77.8)$ \\
\hline Hypertension $[n(\%)]$ & $295(51.8)$ & $134(43.4)$ & $161(61.7)$ \\
\hline Dyslipidemia $[n(\%)]$ & $317(55.6)$ & $137(44.3)$ & $180(69.0)$ \\
\hline Diabetes mellitus $[n(\%)]$ & $99(17.4)$ & $40(12.9)$ & $59(22.6)$ \\
\hline $\begin{array}{l}\text { Positive family history } \\
{[n(\%)]}\end{array}$ & $293(51.5)$ & $140(45.5)$ & $153(58.6)$ \\
\hline Smoking [n (\%)] & $164(28.8)$ & $115(37.2)$ & $49(18.8)$ \\
\hline $\begin{array}{l}\text { Peripheral artery disease } \\
{[n(\%)]}\end{array}$ & $36(6.3)$ & $12(3.9)$ & $24(9.2)$ \\
\hline $\begin{array}{l}\text { Previous myocardial } \\
\text { infarction }[n(\%)]\end{array}$ & $184(32.3)$ & $80(25.9)$ & $104(39.8)$ \\
\hline Previous $\mathrm{PCl}[n(\%)]$ & $185(32.5)$ & $57(18.4)$ & $128(49.0)$ \\
\hline Previous CABG [ $n(\%)]$ & $18(3.2)$ & $7(2.3)$ & $11(4.2)$ \\
\hline Previous stroke $[n(\%)]$ & $23(4.0)$ & $10(3.2)$ & $13(5.0)$ \\
\hline $\begin{array}{l}\text { History of renal } \\
\text { insufficiency }[n(\%)]\end{array}$ & $32(5.6)$ & $13(4.2)$ & $19(7.3)$ \\
\hline $\begin{array}{l}\text { Fibrinogen [median } \\
\text { (interquartile range)] } \\
\text { (g/l) }\end{array}$ & $3.5(2.9-4.4)$ & $3.6(3.0-4.5)$ & $3.4(2.8-4.3)$ \\
\hline \multicolumn{4}{|c|}{ Procedural characteristics $[n(\%)]$} \\
\hline $\mathrm{PCl}$ performed & $501(87.9)$ & 287 (92.9) & $214(82.0)$ \\
\hline \multicolumn{4}{|c|}{ Indication for catheterization } \\
\hline ACS & $309(54.2)$ & $309(100)$ & NA \\
\hline $\begin{array}{l}\text { Myocardial } \\
\text { infarction }\end{array}$ & $159(27.9)$ & $159(51.5)$ & NA \\
\hline SAP & $261(45.8)$ & NA & $261(100)$ \\
\hline \multicolumn{4}{|l|}{ Coronary artery disease } \\
\hline $\begin{array}{l}\text { No significant } \\
\text { stenosis }\end{array}$ & $42(7.4)$ & $18(5.8)$ & $24(9.2)$ \\
\hline One-vessel disease & $301(52.8)$ & $168(54.4)$ & $133(51.0)$ \\
\hline Two-vessel disease & $166(29.1)$ & $88(28.5)$ & 78 (29.9) \\
\hline $\begin{array}{l}\text { Three-vessel } \\
\text { disease }\end{array}$ & $61(10.7)$ & $35(11.3)$ & $26(10.0)$ \\
\hline
\end{tabular}

ACS, acute coronary syndrome; CABG, coronary artery bypass graft surgery; NA, not applicable; $\mathrm{PCl}$, percutaneous coronary intervention; SAP, stable angina pectoris. this was $3.6(3.0-4.5)$ and $3.4(2.8-4.3) \mathrm{g} / \mathrm{l}$, respectively $(P=0.028)$.

The results of the univariable and multivariable analyses for the associations between plasma fibrinogen level and degree and composition of coronary atherosclerosis are shown in Table 2 for the full cohort, in Table 3 for ACS, and in Table 4 for SAP. The degree of atherosclerosis in each group is graphically presented per fibrinogen tertile in Figs 1 and 2. There seemed to be a trend toward higher segment $\mathrm{PB}$ ( $P$ for trend $=0.008$ full cohort; $P$ for trend $=0.014$ ACS subgroup) and a higher prevalence of lesions with $\mathrm{PB} 70 \%$ or more $(P$ for trend $=0.002$ full cohort; $P$ for trend $=0.001$ ACS subgroup) with increasing fibrinogen levels. Specifically, fibrinogen showed a tendency toward a positive association with segment $\mathrm{PB}[\beta$ (95\% CI): $2.55(-0.52-5.61)$ increase in \%PB per $\ln (\mathrm{g} / \mathrm{l})$ fibrinogen, $P=0.09$ ] in the full cohort (Table 2, model 2, Fig. 1), which was driven by a significant association in the ACS subgroup [ $\beta$ (95\% CI): $4.11(0.01-8.21)$ increase in $\% \mathrm{~PB}$ per $\ln (\mathrm{g} / \mathrm{l})$ fibrinogen, $P=0.049$ ] (Table 3 , model 2, Fig. 1). Fibrinogen was also associated with the presence of lesions with $\mathrm{PB} 70 \%$ or more in both the full cohort [OR (95\% CI): $2.27 \quad(1.17-4.43), \quad P=0.016]$ (Table 2, model 2, Fig. 2) and ACS patients [OR (95\% CI): $2.92(1.17-7.29), P=0.022$ ] (Table 3, model 2, Fig. 2). This association did not reach statistical significance in the SAP subgroup [OR (95\% CI): 1.69 (0.62-4.59), $P=0.30$ ] (Table 4, model 2, Fig. 2). After additional adjustment for CRP, statistical significance was no longer reached for any of the associations (model 3 in Tables 2-4).

With respect to the composition and vulnerability of atherosclerosis, in the full cohort, fibrinogen was associated positively with $\mathrm{NC}$ volume $[\beta(95 \% \mathrm{CI}): 0.83$ $(0.11-1.54) \mathrm{mm}^{3}$ increase in $\mathrm{NC}$ volume per $\ln (\mathrm{g} / \mathrm{l})$ fibrinogen, $P=0.024]$ and $\mathrm{FI}$ tissue [ $\beta(95 \% \mathrm{CI}): 0.99$ $(0.01-1.96) \mathrm{mm}^{3}$ increase in FI volume per $\ln (\mathrm{g} / \mathrm{l})$ fibrinogen, $P=0.047$ ] (Table 2, model 2). However, fibrinogen was not associated with the presence of VH-TCFA lesions (i.e. rupture-prone coronary plaques). No associations with composition were present in the ACS and SAP subgroups. After additional adjustment for CRP, again, statistical significance was no longer reached for any of the associations (model 3 in Tables 2-4).

We have described the individual associations of CRP, IL-6, and PAI-1 with the degree, composition, and vulnerability of atherosclerosis in this cohort in earlier reports [23-25]. Briefly, we found that CRP was associated with degree, but not composition or vulnerability of atherosclerosis, and IL-6 and PAI-1 did not show significant associations with any of the plaque characteristics. In the present study, trend analysis showed that patients with both elevated fibrinogen and CRP levels have higher segment $\mathrm{PB}(P$ for trend $=0.041)$ and a higher prevalence of lesions with $\mathrm{PB} 70 \%$ or more $(P$ for 
Table 2 Association between fibrinogen and virtual histology-intravascular ultrasound segment and lesion characteristics in the full cohort $(n=570)$

\begin{tabular}{|c|c|c|c|c|c|c|}
\hline \multirow[b]{2}{*}{ VH-IVUS segment characteristics } & \multicolumn{2}{|c|}{ Model 1 (linear regression) ${ }^{a}$} & \multicolumn{2}{|c|}{ Model 2 (linear regression) $^{b}$} & \multicolumn{2}{|c|}{ Model 3 (linear regression) $^{\mathrm{C}}$} \\
\hline & $\beta(95 \% \mathrm{Cl})$ & $P$-value & $\beta(95 \% \mathrm{Cl})$ & $P$-value & $\beta(95 \% \mathrm{Cl})$ & $P$-value \\
\hline \multicolumn{7}{|l|}{ Degree of atherosclerosis } \\
\hline Plaque volume $\left(\mathrm{mm}^{3}\right)^{\mathrm{d}}$ & $0.12(-0.04$ to 0.28$)$ & 0.15 & $0.12(-0.04$ to 0.28$)$ & 0.15 & $0.02(-0.15$ to 0.20$)$ & 0.79 \\
\hline Plaque burden (\%) & $2.53(-0.48$ to 5.54$)$ & 0.10 & $2.55(-0.52$ to 5.61$)$ & 0.09 & $0.84(-2.49$ to 4.17$)$ & 0.62 \\
\hline \multicolumn{7}{|l|}{ Composition of atherosclerosis } \\
\hline $\mathrm{Fl}$ volume $\left(\mathrm{mm}^{3}\right)^{\mathrm{d}}$ & 1.01 (0.06 to 1.96$)$ & 0.037 & $0.99(0.01$ to 1.96$)$ & 0.047 & $0.46(-0.60$ to 1.52$)$ & 0.39 \\
\hline FF volume $\left(\mathrm{mm}^{3}\right)^{\mathrm{d}}$ & $0.14(-0.14$ to 0.42$)$ & 0.32 & $0.15(-0.13$ to 0.43$)$ & 0.30 & $0.002(-0.31$ to 0.31$)$ & 0.99 \\
\hline NC volume $\left(\mathrm{mm}^{3}\right)^{d}$ & $0.81(0.11$ to 1.51$)$ & 0.024 & $0.83(0.11$ to 1.54$)$ & 0.024 & $0.46(-0.32$ to 1.24$)$ & 0.25 \\
\hline \multirow[t]{2}{*}{ DC volume $\left(\mathrm{mm}^{3}\right)^{\mathrm{d}}$} & $0.18(-0.13$ to 0.48$)$ & 0.25 & $0.21(-0.10$ to 0.52$)$ & 0.18 & $0.07(-0.27$ to 0.41$)$ & 0.68 \\
\hline & \multicolumn{2}{|c|}{ Model 1 (logistic regression) $^{\mathrm{a}}$} & \multicolumn{2}{|c|}{ Model 2 (logistic regression) ${ }^{\mathrm{b}}$} & \multicolumn{2}{|c|}{ Model 3 (logistic regression) ${ }^{\mathrm{C}}$} \\
\hline characteristics & OR $(95 \% \mathrm{Cl})$ & $P$-value & OR $(95 \% \mathrm{Cl})$ & $P$-value & OR $(95 \% \mathrm{Cl})$ & $P$-value \\
\hline \multicolumn{7}{|l|}{ Degree of atherosclerosis } \\
\hline$\geq 1$ lesion with $M L A \leq 4.0 \mathrm{~mm}^{2}$ & $0.59(0.32-1.07)$ & 0.08 & $0.59(0.32-1.10)$ & 0.10 & $0.60(0.30-1.19)$ & 0.14 \\
\hline $\begin{array}{l}\geq 1 \text { lesion with plaque burden } \\
\geq 70 \%\end{array}$ & $2.15(1.12-4.11)$ & 0.021 & $2.27(1.17-4.43)$ & 0.016 & $1.90(0.91-3.97)$ & 0.09 \\
\hline \multicolumn{7}{|l|}{ Composition of atherosclerosis } \\
\hline$\geq 1$ TCFA & $1.02(0.59-1.75)$ & 0.95 & $0.93(0.53-1.63)$ & 0.80 & $0.83(0.45-1.53)$ & 0.54 \\
\hline
\end{tabular}

$\beta$ Indicates the increase in each (transformed) VH-IVUS segment parameter per unit increase in the logarithm (In)-transformed fibrinogen level. OR in the presence of highrisk lesions per unit increase in the In-transformed fibrinogen level.

$\mathrm{Cl}$, confidence interval; DC, dense calcium; FF, fibrofatty; Fl, fibrous; MLA, minimal lumen area; NC, necrotic core; OR, odds ratio; TCFA, thin-cap fibroatheroma; VH-IVUS, virtual histology-intravascular ultrasound.

${ }^{\mathrm{a}}$ Model 1 (univariable) adjusted for age and sex.

${ }^{b}$ Model 2 (multivariable) adjusted for established risk factors (age, sex, smoking, diabetes mellitus, hypertension, and dyslipidemia) and indication for catheterization.

${ }^{c}$ Model 3 (multivariable) adjusted for established risk factors, indication for catheterization, and additionally for C-reactive protein.

dVariables with a non-normal distribution were transformed by the natural In or square root.

Table 3 Association between fibrinogen and virtual histology-intravascular ultrasound segment and lesion characteristics in acute coronary syndrome patients

\begin{tabular}{|c|c|c|c|c|c|c|}
\hline \multirow[b]{3}{*}{ VH-IVUS segment characteristics } & \multicolumn{6}{|c|}{ ACS patients $(n=309)$} \\
\hline & \multicolumn{2}{|c|}{ Model 1 (linear regression) ${ }^{\mathrm{a}}$} & \multicolumn{2}{|c|}{ Model 2 (linear regression) ${ }^{\mathrm{b}}$} & \multicolumn{2}{|c|}{ Model 3 (linear regression) $^{\mathrm{C}}$} \\
\hline & $\beta(95 \% \mathrm{Cl})$ & $P$-value & $\beta(95 \% \mathrm{Cl})$ & $P$-value & $\beta(95 \% \mathrm{Cl})$ & $P$-value \\
\hline \multicolumn{7}{|l|}{ Degree of atherosclerosis } \\
\hline Plaque volume $\left(\mathrm{mm}^{3}\right)^{d}$ & $0.14(-0.08$ to 0.35$)$ & 0.21 & $0.13(-0.09$ to 0.35$)$ & 0.25 & $0.05(-0.20$ to 0.29$)$ & 0.71 \\
\hline Plaque burden (\%) & $4.47(0.43$ to 8.51$)$ & 0.030 & $4.11(0.01$ to 8.21$)$ & 0.049 & $2.26(-2.28$ to 6.81$)$ & 0.33 \\
\hline \multicolumn{7}{|l|}{ Composition of atherosclerosis } \\
\hline FI volume $\left(\mathrm{mm}^{3}\right)^{\mathrm{d}}$ & $0.99(-0.28$ to 2.26$)$ & 0.13 & $0.90(-0.39$ to 2.19$)$ & 0.17 & $0.32(-1.11$ to 1.75$)$ & 0.66 \\
\hline FF volume $\left(\mathrm{mm}^{3}\right)^{d}$ & $0.19(-0.18$ to 0.56$)$ & 0.31 & $0.20(-0.17$ to 0.58$)$ & 0.29 & $0.05(-0.37$ to 0.47$)$ & 0.82 \\
\hline $\mathrm{NC}$ volume $\left(\mathrm{mm}^{3}\right)^{\mathrm{d}}$ & $0.71(-0.22$ to 1.63$)$ & 0.13 & $0.65(-0.29$ to 1.59$)$ & 0.17 & $0.32(-0.72$ to 1.37$)$ & 0.54 \\
\hline $\mathrm{DC}$ volume $\left(\mathrm{mm}^{3}\right)^{\mathrm{d}}$ & $0.25(-0.15$ to 0.65$)$ & 0.22 & $0.26(-0.15$ to 0.67$)$ & 0.22 & $0.16(-0.29$ to 0.62$)$ & 0.48 \\
\hline \multirow{2}{*}{$\begin{array}{l}\text { VH-IVUS high-risk lesion } \\
\text { characteristics }\end{array}$} & \multicolumn{2}{|c|}{ Model 1 (logistic regression) ${ }^{a}$} & \multicolumn{2}{|c|}{ Model 2 (logistic regression) $)^{\mathrm{b}}$} & \multicolumn{2}{|c|}{ Model 3 (logistic regression) $^{\mathrm{c}}$} \\
\hline & OR $(95 \% \mathrm{Cl})$ & $P$-value & OR $(95 \% \mathrm{Cl})$ & $P$-value & OR $(95 \% \mathrm{Cl})$ & $P$-value \\
\hline \multicolumn{7}{|l|}{ Degree of atherosclerosis } \\
\hline$\geq 1$ lesion with $\mathrm{MLA} \leq 4.0 \mathrm{~mm}^{2}$ & $0.75(0.33-1.72)$ & 0.50 & $0.72(0.30-1.74)$ & 0.47 & $0.81(0.30-2.14)$ & 0.67 \\
\hline $\begin{array}{l}\geq 1 \text { lesion with plaque } \\
\text { burden } \geq 70 \%\end{array}$ & $2.84(1.17-6.91)$ & 0.022 & $2.92(1.17-7.29)$ & 0.022 & $2.18(0.77-6.18)$ & 0.14 \\
\hline \multicolumn{7}{|l|}{ Composition of atherosclerosis } \\
\hline$\geq 1$ TCFA & $0.85(0.42-1.75)$ & 0.66 & $0.77(0.37-1.61)$ & 0.48 & $0.68(0.30-1.55)$ & 0.36 \\
\hline
\end{tabular}

$\beta$ Indicates the increase in each VH-IVUS segment parameter per unit increase in the logarithm (In)-transformed fibrinogen level. OR in the presence of high-risk lesions per unit increase in the In-transformed fibrinogen level.

ACS, acute coronary syndrome; Cl, confidence interval; DC, dense calcium; FF, fibrofatty; FI, fibrous; MLA, minimal lumen area; NC, necrotic core; OR, odds ratio; TCFA, thin-cap fibroatheroma; VH-IVUS, virtual histology-intravascular ultrasound.

aModel 1 (univariable) adjusted for age and sex.

${ }^{b}$ Model 2 (multivariable) adjusted for established risk factors (age, sex, smoking, diabetes mellitus, hypertension, and dyslipidemia).

'Model 3 (multivariable) adjusted for established risk factors and additionally for C-reactive protein.

${ }^{d}$ Variables with a non-normal distribution were transformed by the natural In or square root. 
Table 4 Association between fibrinogen and virtual histology-intravascular ultrasound segment and lesion characteristics in stable angina pectoris patients

\begin{tabular}{|c|c|c|c|c|c|c|}
\hline \multirow[b]{3}{*}{ VH-IVUS segment characteristics } & \multicolumn{6}{|c|}{ SAP patients $(n=261)$} \\
\hline & \multicolumn{2}{|c|}{ Model 1 (linear regression) $^{a}$} & \multicolumn{2}{|c|}{ Model 2 (linear regression) $^{b}$} & \multicolumn{2}{|c|}{ Model 3 (linear regression) $^{c}$} \\
\hline & $\beta(95 \% \mathrm{Cl})$ & $P$-value & $\beta(95 \% \mathrm{Cl})$ & $P$-value & $\beta(95 \% \mathrm{Cl})$ & $P$-value \\
\hline \multicolumn{7}{|l|}{ Degree of atherosclerosis } \\
\hline Plaque volume $\left(\mathrm{mm}^{3}\right)^{\mathrm{d}}$ & $0.12(-0.13$ to 0.36$)$ & 0.35 & $0.09(-0.16$ to 0.34$)$ & 0.50 & $-0.005(-0.27$ to 0.26$)$ & 0.97 \\
\hline Plaque burden (\%) & $0.64(-3.93$ to 5.20$)$ & 0.78 & $-0.14(-4.85$ to 4.58$)$ & 0.95 & $-1.32(-6.29$ to 3.65$)$ & 0.60 \\
\hline \multicolumn{7}{|l|}{ Composition of atherosclerosis } \\
\hline FI volume $\left(\mathrm{mm}^{3}\right)^{d}$ & $1.17(-0.31$ to 2.65$)$ & 0.12 & $1.02(-0.50$ to 2.54$)$ & 0.19 & $0.62(-0.99$ to 2.22$)$ & 0.45 \\
\hline FF volume $\left(\mathrm{mm}^{3}\right)^{\mathrm{d}}$ & $0.14(-0.28$ to 0.57$)$ & 0.51 & $0.05(-0.38$ to 0.49$)$ & 0.81 & $-0.06(-0.52$ to 0.40$)$ & 0.80 \\
\hline NC volume $\left(\mathrm{mm}^{3}\right)^{\mathrm{d}}$ & $1.02(-0.08$ to 2.12$)$ & 0.07 & $0.91(-0.22$ to 2.04$)$ & 0.12 & $0.59(-0.61$ to 1.79$)$ & 0.33 \\
\hline \multirow[t]{2}{*}{ DC volume $\left(\mathrm{mm}^{3}\right)^{\mathrm{d}}$} & $0.16(-0.32$ to 0.63$)$ & 0.51 & $0.10(-0.39$ to 0.59$)$ & 0.68 & $-0.04(-0.55$ to 0.47$)$ & 0.88 \\
\hline & \multicolumn{2}{|c|}{ Model 1 (logistic regression) $^{\mathrm{a}}$} & \multicolumn{2}{|c|}{ Model 2 (logistic regression) ${ }^{b}$} & \multicolumn{2}{|c|}{ Model 3 (logistic regression) $^{\mathrm{c}}$} \\
\hline characteristics & OR $(95 \% \mathrm{Cl})$ & $P$-value & OR $(95 \% \mathrm{Cl})$ & $P$-value & OR $(95 \% \mathrm{Cl})$ & $P$-value \\
\hline \multicolumn{7}{|l|}{ Degree of atherosclerosis } \\
\hline$\geq 1$ lesion with $M L A \leq 4.0 \mathrm{~mm}^{2}$ & $0.47(0.19-1.15)$ & 0.10 & $0.41(0.16-1.05)$ & 0.06 & $0.41(0.15-1.09)$ & 0.07 \\
\hline $\begin{array}{l}\geq 1 \text { lesion with plaque } \\
\quad \text { burden } \geq 70 \%\end{array}$ & $1.81(0.69-4.77)$ & 0.23 & $1.69(0.62-4.59)$ & 0.30 & $1.61(0.56-4.66)$ & 0.38 \\
\hline \multicolumn{7}{|l|}{ Composition of atherosclerosis } \\
\hline$\geq 1$ TCFA & $1.13(0.48-2.65)$ & 0.79 & $1.07(0.44-2.59)$ & 0.89 & $0.98(0.38-2.52)$ & 0.97 \\
\hline
\end{tabular}

$\beta$ Indicates the increase in each VH-IVUS segment parameter per unit increase in logarithm (In)-transformed fibrinogen level. OR in presence of high-risk lesions per unit increase in In-transformed fibrinogen level.

$\mathrm{Cl}$, confidence interval; DC, dense calcium; FF, fibrofatty; FI, fibrous; MLA, minimal lumen area; NC, necrotic core; OR, odds ratio; SAP, stable angina pectoris; TCFA, thincap fibroatheroma; VH-IVUS, virtual histology-intravascular ultrasound.

${ }^{\text {aModel }} 1$ (univariable) adjusted for age and sex.

${ }^{b}$ Model 2 (multivariable) adjusted for established risk factors (age, sex, smoking, diabetes mellitus, hypertension, and dyslipidemia).

${ }^{c}$ Model 3 (multivariable) adjusted for established risk factors and additionally for C-reactive protein.

dVariables with a non-normal distribution were transformed by the natural In or square root.

Fig. 1

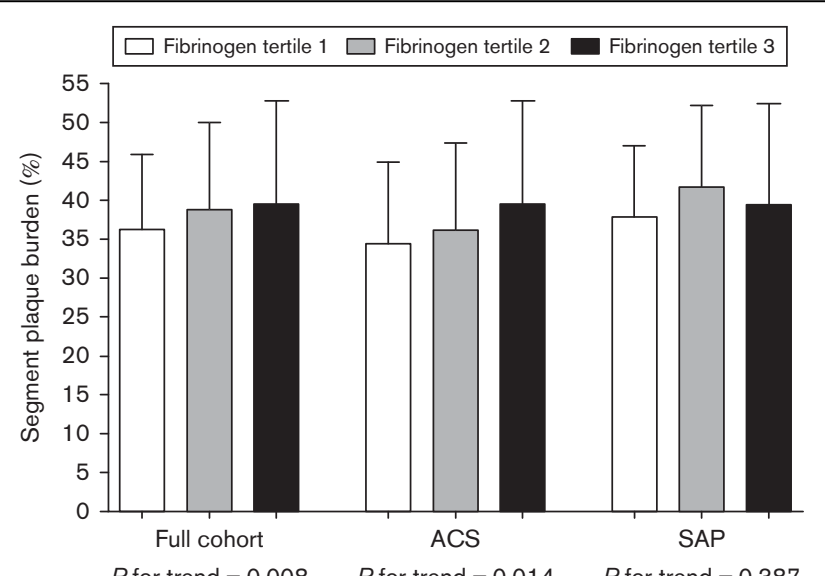

Segment plaque burden (\%) in relation to fibrinogen tertiles. Observed absolute values of segment plaque burden (\%) per fibrinogen tertile in the full cohort and stratified groups. The ANOVA trend test was used to calculate the $P$-values for trend and thus to discern trends across the categories. ACS, acute coronary syndrome; SAP, stable angina pectoris.

trend $=0.090)$, especially in the ACS subgroup ( $P$ for trend $=0.001$ ) (Figs 3 and 4 ). Such a trend could not be found for fibrinogen in combination with IL-6 or PAI-1 (Figs 5-8).
Fig. 2

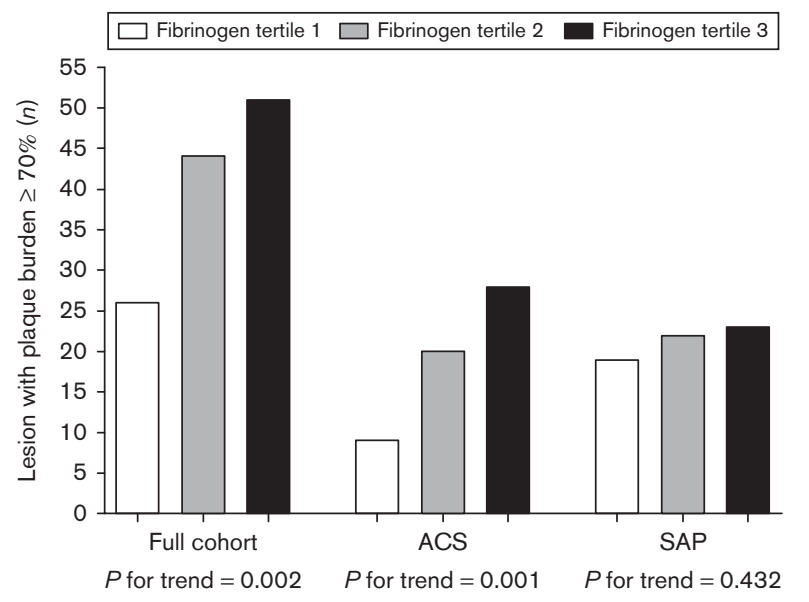

Presence of lesions with plaque burden $70 \%$ or more in relation to fibrinogen tertiles. Observed numbers of lesions with plaque burden $70 \%$ or more per fibrinogen tertile in the full cohort and stratified groups. The ANOVA trend test was used to calculate the $P$-values for trend and thus to discern trends across the categories. ACS, acute coronary syndrome; SAP, stable angina pectoris.

With respect to clinical outcome (results not shown), in the full cohort as well as in the individual ACS and SAP subgroups, no association was found between fibrinogen and MACE. A borderline significant univariable association 
Fig. 3

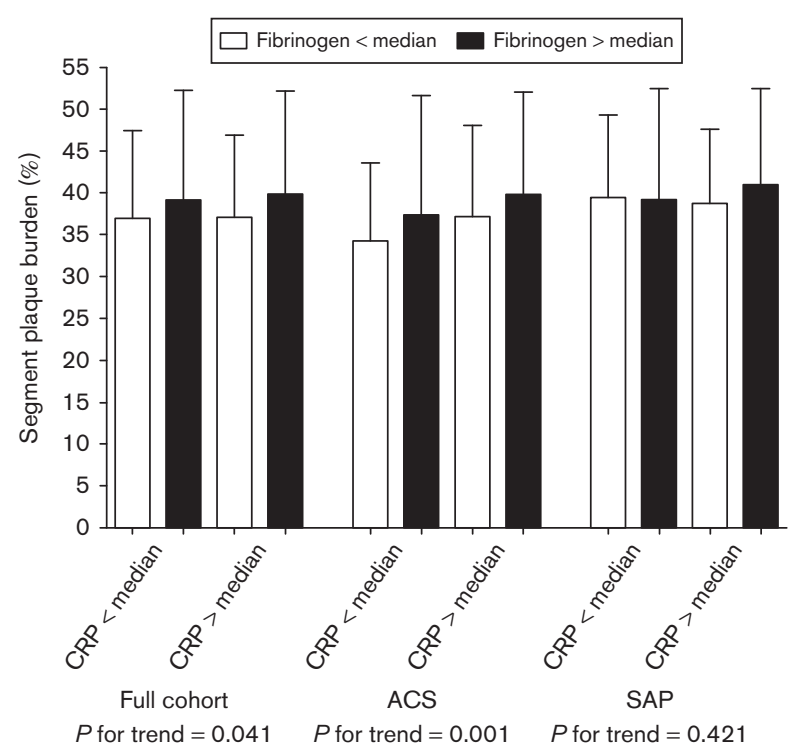

Segment plaque burden (\%) in relation to combined dichotomized CRP and fibrinogen levels. Observed absolute values of segment plaque burden (\%) per category of CRP (above or under median) and fibrinogen (above or under median) together in the full cohort and stratified groups. The ANOVA trend test was used to calculate the $P$-values for trend and thus to discern trends across the categories. ACS, acute coronary syndrome; CRP, C-reactive protein; SAP, stable angina pectoris.

Fig. 4

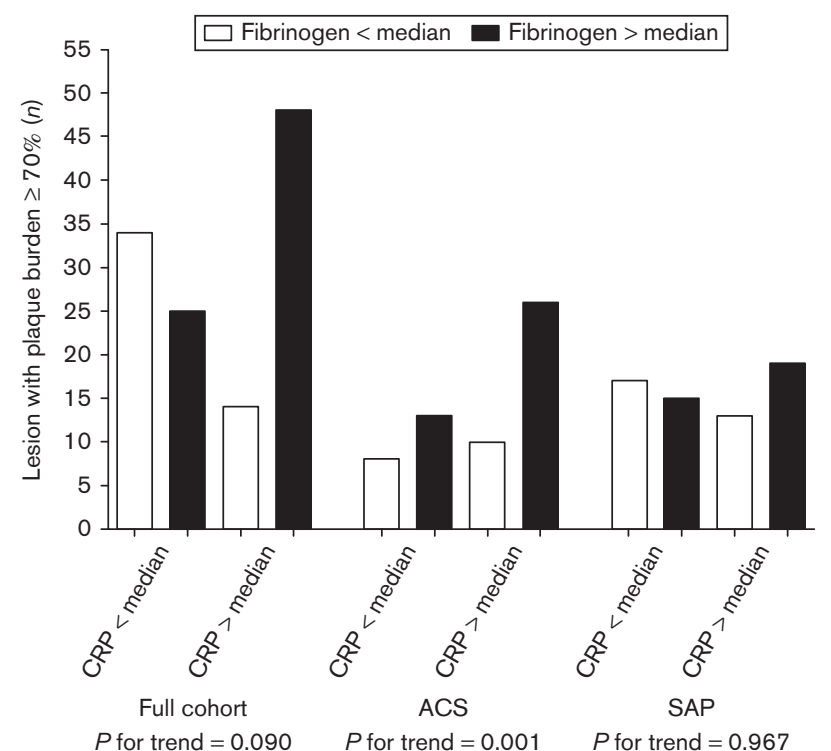

Presence of lesions with plaque burden $70 \%$ or more in relation to combined dichotomized CRP and fibrinogen levels. Observed numbers of lesions with plaque burden $70 \%$ or more per category of CRP (above or under median) and fibrinogen (above or under median) together in the full cohort and stratified groups. The ANOVA trend test was used to calculate the $P$-values for trend and thus to discern trends across the categories. ACS, acute coronary syndrome; CRP, C-reactive protein; SAP, stable angina pectoris.
Fig. 5

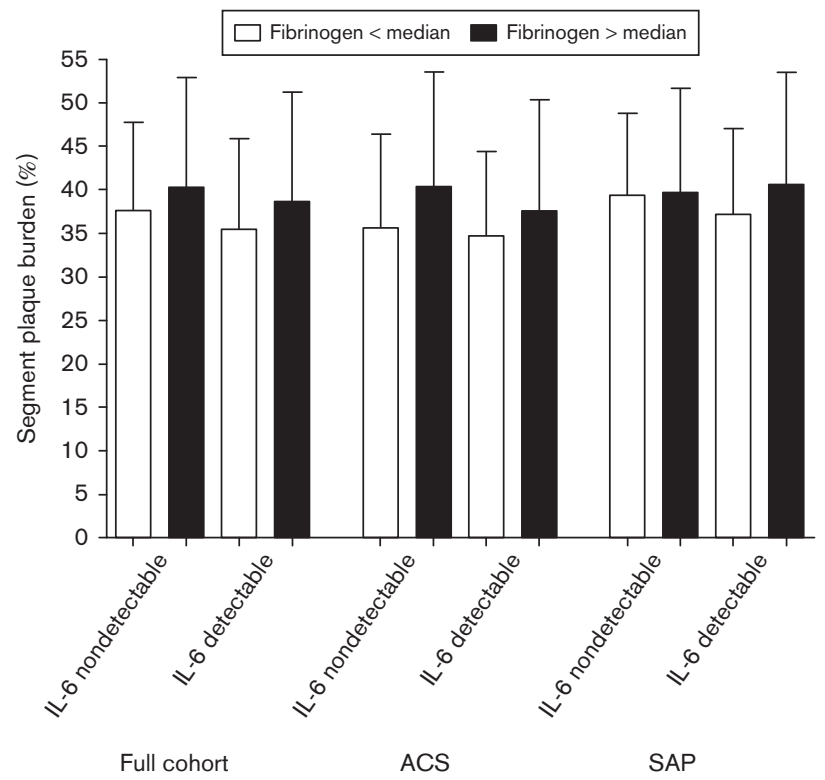

Segment plaque burden (\%) in relation to combined dichotomized IL-6 and fibrinogen levels. Observed absolute values of segment plaque burden (\%) per category of IL-6 (detectable or nondetectable) and fibrinogen (above or under median) together in the full cohort and stratified groups. ACS, acute coronary syndrome; IL-6, interleukin-6; SAP, stable angina pectoris.

Fig. 6

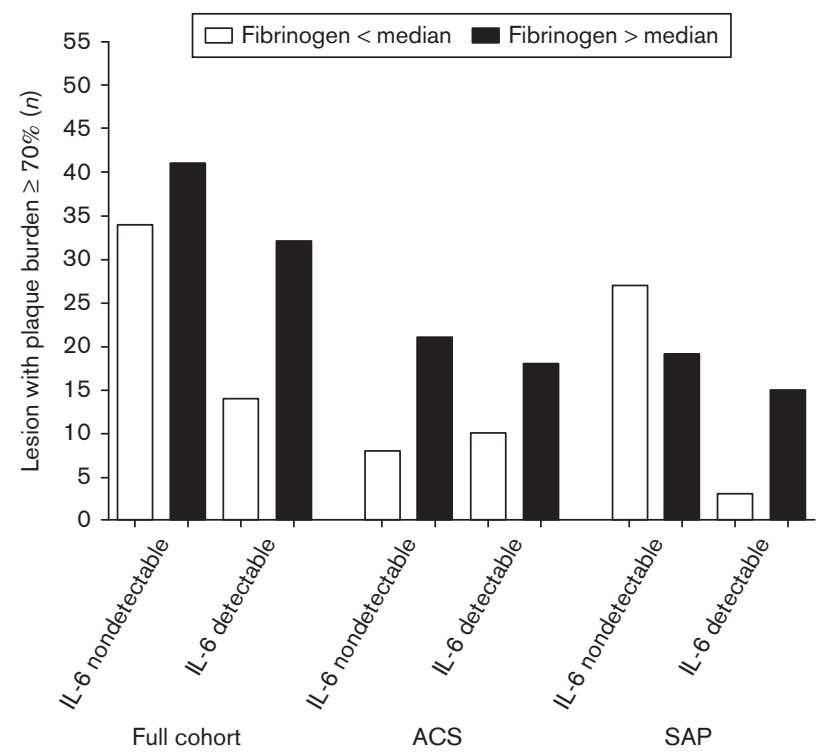

Presence of lesions with plaque burden $70 \%$ or more in relation to combined dichotomized IL- 6 and fibrinogen levels. Observed numbers of lesions with plaque burden $70 \%$ or more per category of IL-6

(detectable or nondetectable) and fibrinogen (above or under median) together in the full cohort and stratified groups. ACS, acute coronary syndrome; IL-6, interleukin-6; SAP, stable angina pectoris. 
Fig. 7

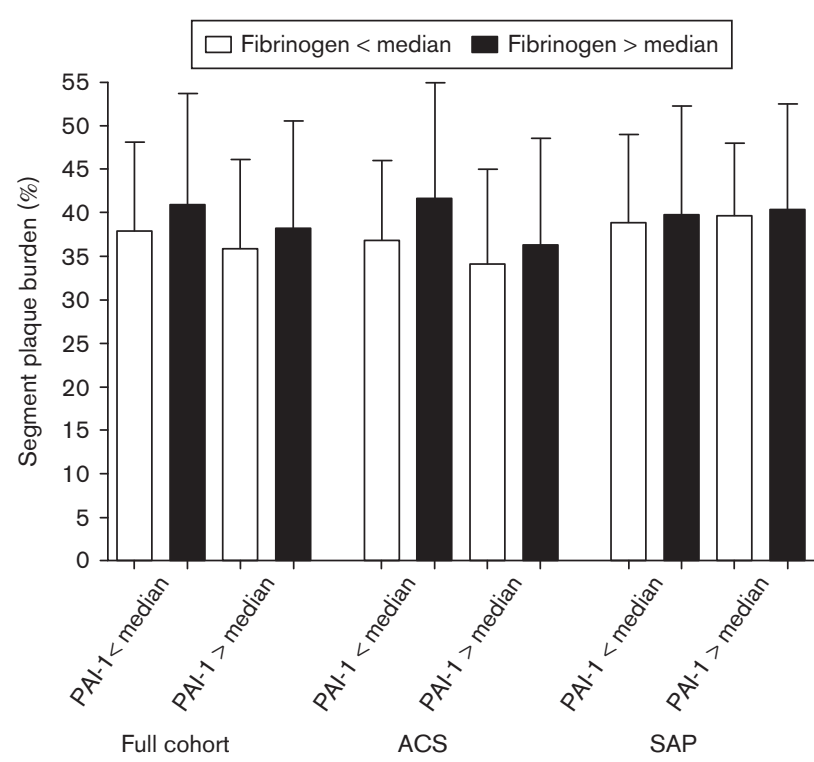

Segment plaque burden (\%) in relation to combined dichotomized PAI-1 and fibrinogen levels. Observed absolute values of segment plaque burden (\%) per category of PAl-1 (above or under median) and fibrinogen (above or under median) together in the full cohort and stratified groups. ACS, acute coronary syndrome; PAI-1, plasminogen activator inhibitor type-1; SAP, stable angina pectoris.

Fig. 8

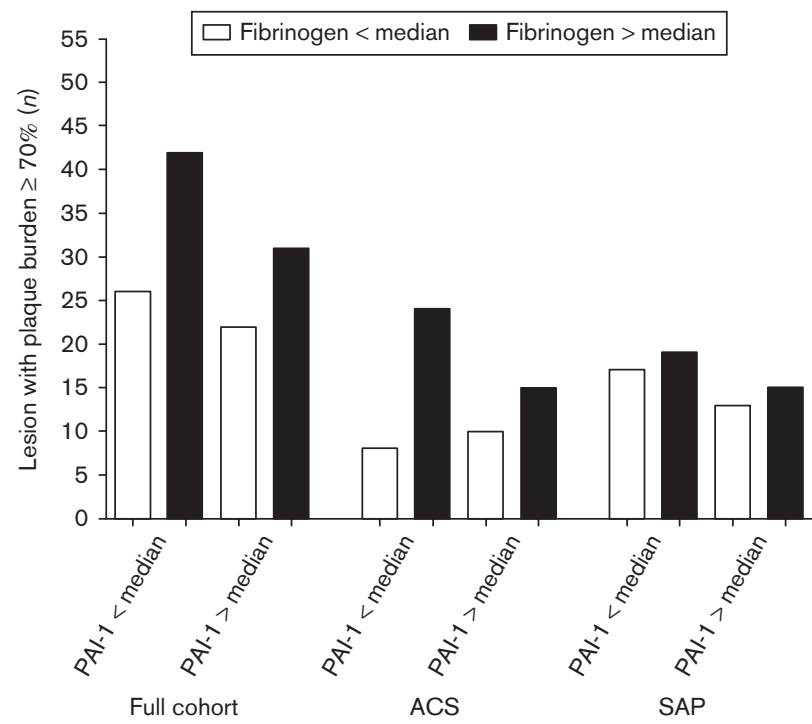

Presence of lesions with plaque burden $70 \%$ or more in relation to combined dichotomized PAl-1 and fibrinogen levels. Observed numbers of lesions with plaque burden $70 \%$ or more per category of PAl-1 (above or under median) and fibrinogen (above or under median) together in the full cohort and stratified groups. ACS, acute coronary syndrome; PAI-1, plasminogen activator inhibitor type-1; SAP, stable angina pectoris.

between fibrinogen and the secondary, composite endpoint of death, or ACS was present in the full cohort [HR (95\% CI): 2.69 (0.99-7.30), $P=0.052$ ]. After adjustment for age and sex, the association became nonsignificant, although the effect estimate remained materially the same [HR (95\% CI): $2.36(0.80-6.93), P=0.12]$. With further adjustment for CRP, the HR became closer to the null [HR (95\% CI): 0.73 (0.20-2.64), $P=0.64]$.

\section{Discussion}

This is the first large study that has investigated the association between plasma fibrinogen level and the degree, composition, and vulnerability of coronary atherosclerotic plaque as assessed by VH-IVUS. Thus, our study provides additional insight into the nature of the relationship between fibrinogen and CAD. We found that fibrinogen was associated with $\mathrm{PB}$ and presence of large lesions, both significantly driven by patients presenting with ACS. Conversely, we could not find substantial associations between fibrinogen and atherosclerotic plaque composition, including VH-IVUS-derived TCFA lesions (i.e. rupture-prone coronary plaques). The latter agrees with an earlier study, which could not find an association between fibrinogen and rupture-prone carotid plaques on ultrasonography [26]. Altogether, these findings might indicate that fibrinogen plays a pathogenic role in the progression of atherosclerotic plaque formation rather than in plaque vulnerability, especially in ACS patients.

Although several studies using different modalities have examined the association between fibrinogen and atherosclerosis, so far, only two studies have applied the IVUS technique [17,18]. Hartmann et al. [17] examined this association with grayscale IVUS in only 60 patients and concluded that fibrinogen levels correlate with plaque progression on IVUS, which is in line with our findings. Yet, the grayscale IVUS technique did not enable examination of plaque composition or plaque vulnerability. The other study, published recently by Corban et al. [18], used the VH-IVUS technique as we did, but the study size was again modest with 75 patients. They concluded that fibrinogen degradation products are associated with larger plaques that have a larger NC. Although they did not stratify their study population by clinical diagnosis (ACS vs. SAP), their findings concur with our results in the full cohort. Here, the authors suggest that fibrinogen may play a role in plaque vulnerability, which should be confirmed in studies that determined TCFAs. However, as the study population was relatively small and consisted of patients with nonobstructive CAD, this study contained a low number of TCFAs. Therefore, the authors could not investigate further whether fibrinogen is associated with plaque vulnerability. In our study, with a relatively large sample size, we could examine the relationship between fibrinogen and TCFAs, but the results did not confirm a relationship with fibrinogen. Therefore, we hypothesize that fibrinogen might rather play a pathogenic role in atherosclerotic plaque formation than in plaque vulnerability. 
A potential association of fibrinogen with degree of coronary plaque is in line with earlier studies, proposing a mechanism by which fibrinogen, as a major determinant of thrombus formation, could directly contribute toward the progression of coronary atherosclerosis [8,27]. Fibrinogen is believed to be involved in an underlying process of multiple consecutive mild episodes of mural thrombosis in response to subclinical rupture [28], leading to repeated incorporation of small thrombi and eventually resulting in gradual progression of an atherosclerotic plaque [29]. This hypothesis is further supported by clinical evidence showing that high fibrinogen levels are positively correlated with the extent of atheroma on coronary angiography $[11,14,30,31]$. Another study that measured the progress of carotid atherosclerosis by high-resolution duplex ultrasound found a temporal relationship between fibrinogen and advanced atherosclerosis rather than with early (inflammatory) stages of the disease [13]. In addition, immunohistochemical studies have shown the presence of fibrinogen in atherosclerotic plaques, indicating that fibrinogen may be directly involved in plaque progression [32].

According to autopsy studies [33], repeated, healed silent plaque ruptures with incorporated organized thrombi are predominantly found in patients with ACS, indicating episodic plaque growth and thereby contributing toward the progression of advanced atherosclerotic plaques in these patients. This might explain the fact that we found a positive association of fibrinogen with degree of coronary atherosclerosis in ACS patients in particular. Rupture-prone, soft, lipid-rich plaques have previously been found to be more common in patients presenting with ACS compared with SAP patients [34]. Taken together with reported findings of increased fibrinogen levels in patients with established advanced CAD [35, 36], the unstable lipid-rich plaques in ACS patients may be more thrombogenic than stable FI plaques in SAP patients [37,38]. Thus, ACS patients with increased fibrinogen levels are likely to have experienced multiple consecutive mild episodes of mural thrombosis previously, eventually leading to a higher degree of atherosclerotic plaque compared with SAP patients.

Another prothrombotic factor that we investigated was PAI-1, which has led to paradoxical results in previous studies [39]. Conflicting results exist with respect to the role of PAI-1 in both promoting and preventing plaque development because of its complex multilevel functions $[39,40]$. We could not find higher or lower degree of coronary plaque in patients with elevated levels of both fibrinogen and PAI-1.

The observed associations of fibrinogen with degree of atherosclerosis were not independent of CRP. CRP has been associated with the presence and degree of atherosclerosis [23,41], and both fibrinogen and CRP are linked to vascular inflammation $[42,43]$. In line with our current results, Hartmann et al. [17] found a positive, but not independent, correlation between fibrinogen levels and plaque progression on IVUS. Furthermore, in our study, a higher degree of atherosclerosis was present in patients with both high levels of CRP and high levels of fibrinogen, suggesting a synergistic effect on coronary atherosclerosis.

Inflammatory processes result in the release of numerous mediators, including IL-6, which is the principal procoagulant cytokine [42]. Although the exact interaction is unknown, it is suggested that IL-6 on its part can increase plasma concentrations of both fibrinogen and CRP, which further amplify inflammatory and procoagulant responses [42]. However, as we have reported earlier, in the current cohort, we found no associations between IL6 and coronary plaque characteristics [25]. Also, in the current investigation, we could not find any trend toward a higher degree of coronary atherosclerosis in patients with both high fibrinogen and high IL-6 levels.

Finally, our data suggest that fibrinogen may be associated with the incidence of all-cause mortality or ACS. The fact that the association became nonsignificant after adjustment for age and sex may have resulted from limited statistical power (56 events after 1-year of follow-up) as the effect estimate remained large after adjustment. However, after additional adjustment for CRP, the associations disappeared completely. Again, common inflammatory grounds may have played a role here. Although population-based studies have shown that fibrinogen is associated with adverse outcome independent of CRP [1], studies in patients with known CAD are fewer in number $[4,5,44]$ and not all of them have taken CRP into account.

Some limitations of this study must be acknowledged. First, the possibility that fibrinogen as an acute-phase reactant may be the result of clinical presentation rather than its cause, particularly in patients with ACS, cannot be excluded. Our study design does not enable causal inference. Nevertheless, our study does provide novel data on fibrinogen in relation to in-vivo assessment of the arterial wall (i.e. more accurate measures of coronary atherosclerosis) [45] and may thus serve to be hypothesis generating. Second, VH-IVUS imaging data were acquired in a nonculprit coronary artery segment only. This approach was based on the hypothesis that such a nonculprit target segment adequately reflects the patient's overall state of coronary wall pathophysiology of the larger coronary vasculature [19]. This hypothesis has been confirmed by several IVUS studies that showed that the coronary wall of a nonculprit segment in a single vessel does reflect larger coronary disease burden and is associated with subsequent cardiovascular events [46,47].

In conclusion, our findings support the hypothesis that fibrinogen is associated with coronary atherosclerotic $\mathrm{PB}$, especially in patients presenting with ACS. However, 
whether this association is independent of CRP may be questioned and warrants further investigation.

\section{Acknowledgements}

The authors thank the following interventional cardiologists and technical staff for their contribution to this study: Eric Duckers, MD, PhD; Willem van der Giessen, MD, PhD; Peter P.T. de Jaegere, MD, PhD; Jurgen M.R. Ligthart; Nicolas M.D.A. van Mieghem, MD, PhD; Carl Schultz, MD, PhD; Karen T. Witberg; and Felix Zijlstra, MD, PhD. They are indebted to Professor Willem van der Giessen, who provided a valuable contribution to the design and completion of the study, but passed away before finalization of this work.

This ATHEROREMO-IVUS study was supported by the European Commission, Seventh Framework Programme (theme FP7-HEALTH-2007-2.4.2-1) and funded by BBMRI-NL (a research infrastructure financed by the Dutch government, NWO 184.021.007) and the Netherlands Heart Foundation (NHS2009B091 to J.M.C. and NHS2007B012 to R.M.O.).

\section{Conflicts of interest}

There are no conflicts of interest.

\section{References}

1 Danesh J, Lewington S, Thompson SG, Lowe GD, Collins R, Kostis JB, et al. Plasma fibrinogen level and the risk of major cardiovascular diseases and nonvascular mortality: an individual participant meta-analysis. JAMA 2005 294:1799-1809.

2 Kannel WB, Wolf PA, Castelli WP, D'Agostino RB. Fibrinogen and risk of cardiovascular disease. The Framingham Study. JAMA 1987; 258:1183-1186.

3 Park CS, Ihm SH, Yoo KD, Kim DB, Lee JM, Kim HY, et al. Relation between C-reactive protein, homocysteine levels, fibrinogen, and lipoprotein levels and leukocyte and platelet counts, and 10-year risk for cardiovascular disease among healthy adults in the USA. Am J Cardio/ 2010; 105:1284-1288.

4 Becker RC, Cannon CP, Bovill EG, Tracy RP, Thompson B, Knatterud GL, et al. Prognostic value of plasma fibrinogen concentration in patients with unstable angina and non-Q-wave myocardial infarction (TIMI IIIB Trial). Am J Cardiol 1996; 78:142-147.

5 Toss H, Lindahl B, Siegbahn A, Wallentin L. Prognostic influence of increased fibrinogen and $\mathrm{C}$-reactive protein levels in unstable coronary artery disease. Circulation 1997; 96:4204-4210.

6 Sinning JM, Bickel C, Messow CM, Schnabel R, Lubos E, Rupprecht HJ, et al. Impact of C-reactive protein and fibrinogen on cardiovascular prognosis in patients with stable angina pectoris: the AtheroGene study. Eur Heart $J$ 2006; 27:2962-2968.

7 Ndrepepa G, Braun S, King L, Fusaro M, Keta D, Cassese S, et al. Relation of fibrinogen level with cardiovascular events in patients with coronary artery disease. Am J Cardiol 2013; 111:804-810.

8 De Moerloose P, Boehlen F, Neerman-Arbez M. Fibrinogen and the risk of thrombosis. Semin Thromb Hemost 2010; 36:7-17.

9 Yee KO, Schwartz SM. Why atherosclerotic vessels narrow: the fibrin hypothesis. Thromb Haemost 1999; 82:762-771.

10 Koenig W. Fibrin(ogen) in cardiovascular disease: an update. Thromb Haemost 2003; 89:601-609.

11 Handa K, Kono S, Saku K, Sasaki J, Kawano T, Sasaki Y, et al. Plasma fibrinogen levels as an independent indicator of severity of coronary atherosclerosis. Atherosclerosis 1989; 77:209-213.

12 Levenson J, Giral P, Razavian M, Gariepy J, Simon A. Fibrinogen and silent atherosclerosis in subjects with cardiovascular risk factors. Arterioscler Thromb Vasc Biol 1995; 15:1263-1268.

13 Willeit J, Kiechl S, Oberhollenzer F, Rungger G, Egger G, Bonora E, et al. Distinct risk profiles of early and advanced atherosclerosis: prospective results from the Bruneck study. Arterioscler Thromb Vasc Biol 2000; 20:529-537.

14 Zhang Y, Zhu CG, Guo YL, Li S, Xu RX, Dong Q, et al. Fibrinogen and the severity of coronary atherosclerosis among adults with and without statin treatment: lipid as a mediator. Heart Lung Circ 2016; 25:558-567.

15 Zhang Y, Zhu CG, Guo YL, Xu RX, Li S, Dong Q, et al. Higher fibrinogen level is independently linked with the presence and severity of new-onset coronary atherosclerosis among Han Chinese population. PLoS One 2014; 9:e113460.

16 Garcia-Garcia HM, Costa MA, Serruys PW. Imaging of coronary atherosclerosis: intravascular ultrasound. Eur Heart J 2010; 31:2456-2469.

17 Hartmann M, von Birgelen C, Mintz GS, Stoel MG, Eggebrecht H, Wieneke $\mathrm{H}$, et al. Relation between lipoprotein(a) and fibrinogen and serial intravascular ultrasound plaque progression in left main coronary arteries. J Am Coll Cardiol 2006; 48:446-452.

18 Corban MT, Hung OY, Mekonnen G, Eshtehardi P, Eapen DJ, RasoulArzrumly $\mathrm{E}$, et al. Elevated levels of serum fibrin and fibrinogen degradation products are independent predictors of larger coronary plaques and greater plaque necrotic core. Circ J 2016; 80:931-937.

19 De Boer SP, Cheng JM, Garcia-Garcia HM, Oemrawsingh RM, van Geuns RJ, Regar E, et al. Relation of genetic profile and novel circulating biomarkers with coronary plaque phenotype as determined by intravascular ultrasound: rationale and design of the ATHEROREMO-IVUS study. Eurolntervention 2014; 10:953-960.

20 Van de Werf F, Bax J, Betriu A, Blomstrom-Lundqvist C, Crea F, Falk V, et al. Management of acute myocardial infarction in patients presenting with persistent ST-segment elevation: the Task Force on the Management of STSegment Elevation Acute Myocardial Infarction of the European Society of Cardiology. Eur Heart J 2008; 29:2909-2945.

21 Hamm CW, Bassand JP, Agewall S, Bax J, Boersma E, Bueno H, et al. ESC Guidelines for the management of acute coronary syndromes in patients presenting without persistent ST-segment elevation: the Task Force for the management of acute coronary syndromes (ACS) in patients presenting without persistent ST-segment elevation of the European Society of Cardiology (ESC). Eur Heart J 2011; 32:2999-3054.

22 Kaptoge S, Di Angelantonio E, Pennells L, Wood AM, White IR, Gao P, et al. $\mathrm{C}$-reactive protein, fibrinogen, and cardiovascular disease prediction. $N$ Engl J Med 2012; 367:1310-1320.

23 Cheng JM, Oemrawsingh RM, Garcia-Garcia HM, Akkerhuis KM, Kardys I, de Boer SP, et al. Relation of C-reactive protein to coronary plaque characteristics on grayscale, radiofrequency intravascular ultrasound, and cardiovascular outcome in patients with acute coronary syndrome or stable angina pectoris (from the ATHEROREMO-IVUS study). Am J Cardio/ 2014; 114:1497-1503.

24 Battes LC, Akkerhuis KM, Cheng JM, Garcia-Garcia HM, Oemrawsingh RM, de Boer SP, et al. Circulating acute phase proteins in relation to extent and composition of coronary atherosclerosis and cardiovascular outcome: results from the ATHEROREMO-IVUS study. Int J Cardiol 2014; 177:847-853.

25 Battes LC, Cheng JM, Oemrawsingh RM, Boersma E, Garcia-Garcia HM, de Boer SP, et al. Circulating cytokines in relation to the extent and composition of coronary atherosclerosis: results from the ATHEROREMO-IVUS study. Atherosclerosis 2014; 236:18-24.

26 Kofoed SC, Wittrup HH, Sillesen H, Nordestgaard BG. Fibrinogen predicts ischaemic stroke and advanced atherosclerosis but not echolucent, ruptureprone carotid plaques: the Copenhagen City Heart Study. Eur Heart J 2003; 24:567-576.

27 Bini A, Kudryk BJ. Fibrinogen in human atherosclerosis. Ann N Y Acad Sci 1995; 748:461-471; discussion 471-463.

28 Zaman AG, Helft G, Worthley SG, Badimon JJ. The role of plaque rupture and thrombosis in coronary artery disease. Atherosclerosis 2000; 149:251-266.

29 Stary HC, Chandler AB, Dinsmore RE, Fuster V, Glagov S, Insull W Jr, et al. A definition of advanced types of atherosclerotic lesions and a histological classification of atherosclerosis. A report from the Committee on Vascular Lesions of the Council on Arteriosclerosis, American Heart Association. Circulation 1995; 92:1355-1374.

30 Broadhurst P, Kelleher C, Hughes L, Imeson JD, Raftery EB. Fibrinogen, factor VII clotting activity and coronary artery disease severity. Atherosclerosis 1990; 85:169-173.

31 Tataru MC, Schulte H, von Eckardstein A, Heinrich J, Assmann G, Koehler E Plasma fibrinogen in relation to the severity of arteriosclerosis in patients with stable angina pectoris after myocardial infarction. Coron Artery Dis 2001; 12:157-165.

32 Bini A, Fenoglio JJ Jr, Mesa-Tejada R, Kudryk B, Kaplan KL. Identification and distribution of fibrinogen, fibrin, and fibrin(ogen) degradation products in atherosclerosis. Use of monoclonal antibodies. Arteriosclerosis 1989; 9:109-121. 
33 Burke AP, Kolodgie FD, Farb A, Weber DK, Malcom GT, Smialek J, et al. Healed plaque ruptures and sudden coronary death: evidence that subclinical rupture has a role in plaque progression. Circulation 2001; 103:934-940.

34 Thieme T, Wernecke KD, Meyer R, Brandenstein E, Habedank D, Hinz A, et al. Angioscopic evaluation of atherosclerotic plaques: validation by histomorphologic analysis and association with stable and unstable coronary syndromes. J Am Coll Cardiol 1996; 28:1-6.

35 Kruskal JB, Commerford PJ, Franks JJ, Kirsch RE. Fibrin and fibrinogenrelated antigens in patients with stable and unstable coronary artery disease. N Engl J Med 1987; 317:1361-1365.

36 [No authors listed]. ECAT angina pectoris study: baseline associations of haemostatic factors with extent of coronary arteriosclerosis and other coronary risk factors in 3000 patients with angina pectoris undergoing coronary angiography. Eur Heart $J$ 1993; 14:8-17

37 Fernandez-Ortiz A, Badimon JJ, Falk E, Fuster V, Meyer B, Mailhac A, et al. Characterization of the relative thrombogenicity of atherosclerotic plaque components: implications for consequences of plaque rupture. J Am Coll Cardiol 1994; 23:1562-1569.

38 Ando H, Amano T, Matsubara T, Uetani T, Nanki M, Marui N, et al. Comparison of tissue characteristics between acute coronary syndrome and stable angina pectoris. An integrated backscatter intravascular ultrasound analysis of culprit and non-culprit lesions. Circ J 2011; 75:383-390.

39 Diebold I, Kraicun D, Bonello S, Gorlach A. The 'PAI-1 paradox' in vascular remodeling. Thromb Haemost 2008; 100:984-991.
40 Ploplis VA. Effects of altered plasminogen activator inhibitor-1 expression on cardiovascular disease. Curr Drug Targets 2011; 12:1782-1789.

41 Elias-Smale SE, Kardys I, Oudkerk M, Hofman A, Witteman JCM. C-reactive protein is related to extent and progression of coronary and extra-coronary atherosclerosis; results from the Rotterdam study. Atherosclerosis 2007; 195:E195-E202.

42 Willerson JT, Ridker PM. Inflammation as a cardiovascular risk factor. Circulation 2004; 109:2-10.

43 Kubo T, Matsuo Y, Hayashi Y, Yamano T, Tanimoto T, Ino Y, et al. High sensitivity $\mathrm{C}$-reactive protein and plaque composition in patients with stable angina pectoris: a virtual histology intravascular ultrasound study. Coron Artery Dis 2009; 20:531-535.

44 Acevedo M, Foody JM, Pearce GL, Sprecher DL. Fibrinogen: associations with cardiovascular events in an outpatient clinic. Am Heart J 2002; 143:277-282.

45 Nasu K, Tsuchikane E, Katoh O, Vince DG, Virmani R, Surmely JF, et al. Accuracy of in vivo coronary plaque morphology assessment: a validation study of in vivo virtual histology compared with in vitro histopathology. $J A m$ Coll Cardiol 2006; 47:2405-2412.

46 Cheng JM, Garcia-Garcia HM, de Boer SPM, Kardys I, Heo JH, Akkerhuis $\mathrm{KM}$, et al. In vivo detection of high-risk coronary plaques by radiofrequency intravascular ultrasound and cardiovascular outcome: results of the ATHEROREMO-IVUS study. Eur Heart J 2014; 35:639-647.

47 Nicholls SJ, Hsu A, Wolski K, Hu B, Bayturan O, Lavoie A, et al. Intravascular ultrasound-derived measures of coronary atherosclerotic plaque burden and clinical outcome. J Am Coll Cardiol 2010; 55:2399-2407. 